\title{
Combined Effects of Flow/Spray Interactions and EGR on Combustion \\ Variability for a Stratified DISI Engine
}

\author{
Wei Zeng ${ }^{\text {a }}$ Magnus Sjöberg ${ }^{a}$, David Reuss ${ }^{\text {a,b }}$ \\ a Sandia National Laboratories, MS 9053, PO Box 969, Livermore, CA 94551-0969, USA \\ b University of Michigan, 1231 Beal Ave., Ann Arbor, MI, 48109, USA
}

\begin{abstract}
This study investigates combustion variability of a stratified-charge direct-injection spark ignited (DISI) engine, operated with near-TDC injection of E70 fuel and a spark timing that occurs during the early part of the fuel injection. Using EGR, low engine-out $\mathrm{NO}_{\mathrm{x}}$ can be achieved, but at the expense of increased combustion variability at higher engine speeds. Initial motored tests at different speeds reveal that the in-cylinder gas flow becomes sufficiently strong at $2000 \mathrm{rpm}$ to cause significant cycle-to-cycle variations of the spray penetration. Hence, the fired tests focus on operation at $2000 \mathrm{rpm}$ with $\mathrm{N}_{2}$ dilution $\left(\left[\mathrm{O}_{2}\right]=19 \%\right.$ and $\left.21 \%\right)$ to simulate EGR. In-cylinder flow, spray, and early-flame measurements are correlated to reveal their effect on the combustion variability.

Results reveal two types of flow/spray-interactions that predict the likelihood of a partial burn. 1) Proper flow direction before injection with a more collapsed spray leads to high kinetic energy of the flow during injection, thus generating a rapid early burn, which ensures complete combustion, regardless of the EGR level. 2) Improper flow direction and less collapsed spray generate low flow energy during the early phase of combustion. For this second type of flow/spray-interaction, application of EGR results in a partial-burn frequency of 30\%, whereas without EGR, early combustion is shown to be insensitive to flow variations. Flame-probability maps illustrate that the partial-burn cycles for operation with EGR have a weak flame development in that the flame does not develop uniformly and reliably from the spark plug. Without EGR, the flame development is more repeatable regardless of the type of flow/spray-interaction, at the expense of higher $\mathrm{NO}_{\mathrm{x}}$ emissions.
\end{abstract}

Key words: Stratified DISI Engine, Combustion variability, Flow/Spray Interactions, EGR, Optical diagnostics 


\section{Introduction}

High efficiency can be achieved in spark-ignited automotive engines using un-throttled stratified-charge combustion for load control. However, practical implementation is inhibited by the need for lean- $\mathrm{NO}_{\mathrm{x}}$ and particulate aftertreatment [1, 2]. Recent studies by the authors have demonstrated that legislated levels of engine-out $\mathrm{NO}_{\mathrm{x}}$ and soot abatement can be achieved using EGR combined with ethanol-gasoline blends, which enable later injection and spray-head ignition compared to pure gasoline. However, the in-cylinder emission control is limited to a small speed and load range due to cyclic variability [3, 4]. Further research has been undertaken to identify the causes of the combustion variability with the goal of expanding the operating range. Testing at 1000 and $2000 \mathrm{rpm}$ led to two hypotheses; a) The spray-guided stratified-charge combustion rate is primarily controlled by the mixing rates and turbulence level associated with fuel injection, but b) the in-cylinder flow field, generated by the intake and compression strokes, stochastically disturbs the mixing and flow associated with the fuel jets, thereby causing cycle-to-cycle variations of the combustion [5]. Particle image velocimetry (PIV), flame and liquidspray measurements of non-fired operation support these hypotheses [6]. In this study, these in-cylinder optical diagnostics are instead applied to fired operation for correlation with the combustion variability. Here, tests are performed at $2000 \mathrm{rpm}$ with and without $\mathrm{N}_{2}$ dilution, and distinct differences in flow and combustion variability are observed.

The PIV measurement focused on the tumble plane right in between the injector tip and the spark plug gap. The $2 \mathrm{D}$ plane chosen allows simultaneous characterizations of the tumble flow and spray structures in the piston bowl. With $2 \mathrm{D}$ tumble plane measurement, investigations $[7,8]$ on interactions of in-cylinder charge motion and sprays from multiple injections have revealed that the first injection significantly perturbed the tumble flow and fluctuations of the resulting flow structures correlated with the spray shape of the second injection. In this study, a single injection strategy is implemented. Statistical analysis is used to correlate the flow and spray structures with both the flow energy during injection and with the appearance of partial-burn cycles. The results provide unique insights of the physics responsible for the impact of flow/spray interaction on combustion variability of highly stratified DISI engine operation.

\section{Experimental setup and methodology}

\subsection{Single cylinder engine}

Testing was performed in a single-cylinder four-valve pent-roof DISI engine, operated with late injection for stratified-charge combustion. In a spray-guided configuration, an eight-hole injector was located near the cylinder axis and oriented with two of the eight jets straddling the ground electrode of the spark plug. The engine was operated in an all-metal configuration for continuously fired performance testing or in a geometrically-identical optical configuration as shown in Fig.1. For optical 
access the Bowditch piston was equipped with a plano-concave ( $\mathrm{R}=25 \mathrm{~mm})$ quartz window to create a flat-bottom piston bowl with a large viewing angle. Also, a flat quartz window was located in the end of the pent-roof section closest to the injector to enable observation along the axis of the pent-roof. E70 fuel was prepared by blending pure ethanol and researchgrade gasoline with $(\mathrm{R}+\mathrm{M}) / 2=87$ in $70 / 30 \%$ proportions by volume [5]. All tests in this study were conducted with one intake valve deactivated to increase in-cylinder swirl and tumble levels, which generally provide more robust stratified operation. For fired engine operation, $\mathrm{N}_{2}$ dilution was used to lower the intake mole fraction of oxygen $\left[\mathrm{O}_{2}\right]$ to simulate EGR. In-cylinder pressure was acquired with $0.1^{\circ}$ crank-angle $(\mathrm{CA})$ resolution for 500 consecutively fired cycles during allmetal engine operations. The apparent heat-release rate (AHRR) was computed from the in-cylinder pressure using a constant ratio of specific heats $(\gamma)$ following Ref. [9]. NO emissions were measured using a Horiba MEXA-584L emission analyzer. Engine specifications and operating conditions are given in Table 1. A complete description of the hardware and analysis is provided in Ref. [5].

\subsection{Optical diagnostics}

High-speed planar PIV and flame natural emission were acquired for Tests $4 \& 5$ to measure the in-cylinder gas flow, fuel injection, and combustion processes. A $25 \%$ duty cycle Fire2-Skip6 sequence was used to reduce the thermal load. Incylinder pressure and optical data were acquired during the second fired cycle to ensure proper temperature and composition of the residual gases.

Details of the PIV measurement hardware, post-processing, and uncertainty analysis are discussed in a companion study [6]. Key parameters are summarized as follows. The PIV images were recorded by a CMOS camera (Phantom v710) through the pent-roof window to provide instantaneous two-dimensional (2D) view of the tumble plane. The piston-bowl rim has a cutout to improve optical access, but the geometry is identical for the optical and metal engine configurations. Laser-sheet location and camera views are shown in Fig.1. The v710-camera was angled downward to view into the bowl creating a systematic $8 \%$ error in the vertical velocity that was uncorrected, but does not affect the comparisons or conclusions in this study. The silicone oil droplets, which have mean diameters of $1 \mu \mathrm{m}$, were illuminated by a $2 \mathrm{~mm}$ thick $532 \mathrm{~nm}$ laser sheet, which was directed through the piston window, normal to the ridge of the pent-roof, and passing between the spark plug and the injector. As discussed in Ref. [6], the relatively thick laser sheet did degrade the in-plane spatial resolution and increase the perspective errors, but does not affect the conclusions of the current study. On the other hand, it reduces out-of-plane seeding particle loss between PIV frames. The dual-cavity laser produced two $4 \mathrm{~mJ}$ pulses with an interval of $10 \mu \mathrm{s}(\Delta \mathrm{t})$ at every $2.0^{\circ} \mathrm{CA}(6 \mathrm{kHz})$. The $1200 \mathrm{x} 440$ pixel PIV image pairs (one pair per $2^{\circ} \mathrm{CA}$ ) were recorded at $12 \mathrm{kHz}$ using frame 
straddling. The 0.75 magnification produced a $47 \times 17 \mathrm{~mm}$ field of view with $0.98 \mathrm{~mm}^{2}$ square $(32 \times 32$ pixel) PIV interrogation spots on a $0.5 \mathrm{~mm}^{2}$ grid. Thus there is an in-plane spatial resolution of $1 \mathrm{~mm}$ and a velocity dynamic range of $0.58-31.3 \mathrm{~m} / \mathrm{s}$. The valid-vector rate was greater than $80 \%$.

Simultaneously with the PIV and spray measurements through the side window (tests 4 \& 5), flame image was acquired every $1^{\circ} \mathrm{CA}(12 \mathrm{kHz})$ through the piston-bowl window by another CMOS camera (Phantom v7.1), using $384 \times 384$ pixel resolution. This imaging was performed via two mirrors; the Bowditch-piston mirror was installed below the piston and a second mirror was located outside the engine with an offset to avoid blocking the laser sheet. A $532 \pm 10 \mathrm{~nm}$ notch filter was installed to reject scattered laser-light. The optical setup is also detailed in Ref. [6]. The spray was illuminated using a highintensity blue LED with a 2- $\mu$ s-pulse duration via the pent-roof end-window.

Separate spray images were acquired in tests $6 \& 7$ to measure the effect of the in-cylinder gas flow on liquid spray variability. Sprays were imaged through the piston-bowl window with a color CMOS camera (Phantom v611) operated at a

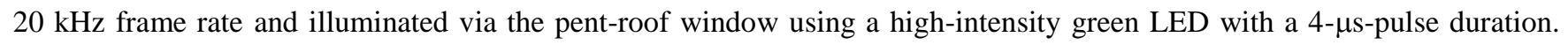
Data were acquired for 200 non-fired cycles at 333 and $2000 \mathrm{rpm}$. These engine speeds were chosen to compare relatively weak and strong in-cylinder flows.

\section{Results and discussion}

\subsection{Engine combustion performance}

All-metal experiments (tests 1-3 in Table 1) for $\left[\mathrm{O}_{2}\right]$ sweep at $2000 \mathrm{rpm}$ were carried out to quantify the effect of EGR on combustion and exhaust emissions, and establish the conditions for optical experiments in tests 4 \& 5. A head-ignition strategy (ignite the leading edge of spray) was applied to achieve closely coupled injection and combustion, which can provide ultra-low NO emissions. Here the soot level is relatively high (FSN $\approx 0.52-0.58$ ). The combined effects of fuel type and ignition strategies on soot emissions are discussed in Ref. [10] but are outside the scope of this discussion. Injection and spark timings were adjusted to achieve $\mathrm{CA} 50 \approx 7-8^{\circ} \mathrm{CA}$. Figure 2 shows that $\mathrm{NO}$ emissions decrease strongly for lower $\left[\mathrm{O}_{2}\right]$, at the expense of elevated combustion variability and decreased combustion efficiency. The importance of realizing both low $\mathrm{NO}_{\mathrm{x}}$ and stable combustion motivates an investigation of the cause of the observed combustion variability. As mentioned in the introduction, at $2000 \mathrm{rpm}$ the in-cylinder flow field generated by the intake and compression strokes becomes sufficiently strong to significantly contribute to cycle-to-cycle variations of the mixing rates and turbulence level associated with the spray. Generally, a reduction of $\left[\mathrm{O}_{2}\right]$ weakens both premixed and non-premixed flames, with an associated reduction of both the flame speed and the strain rate where extinction occurs. With respect to Fig. 2, it is then hypothesized that for low $\left[\mathrm{O}_{2}\right]$, 
the flame weakens sufficiently to the point of being susceptible to variations of flow/spray interactions, occasionally degrading the combustion efficiency, thereby elevating the variability of IMEP $_{g}$ (indicated mean effective pressure-gross). To examine the validity of this hypothesis, optical diagnostics were applied for fired operations with $\left[\mathrm{O}_{2}\right]=21 \%$ and $19 \%$ (tests $4 \& 5$ ). Flow variations before and during injection, and their effects on spray development and flame propagation are studied. For test 5, seven partial-burn cycles are observed out of the total 140 cycles, while all cycles from test 4 burn well. Here, partial burns are defined to have a final mass fraction burned (FMFB) below $80 \%$.

\subsection{Variations of liquid spray}

Spray Mie-scattering images (tests 6\&7) for $2000 \mathrm{rpm}$ are shown in Fig. 3a to reveal the effect of in-cylinder flow variability on liquid spray. The images are shown at $0.20 \mathrm{~ms}$ after start of injection (ASOI $)$, corresponding to $20 \%$ of the injection duration. The difference in the location of the sprays relative to the overlay for both examples indicates that the liquid jets appear to rotate in unison from cycle to cycle. Variations in individual plume spread and jet trajectory are also observed. In addition, a significant variation of radial penetration (defined in Fig. 3b) is observed for the 1:00- and 11:00-jets. The

threshold is defined according to the SAE Standard-J2715. To quantify this, Fig. 3b presents average penetration of the 1:00jet and its coefficient of variation (COV) for 333 and $2000 \mathrm{rpm}$. The disparate engine speeds (and thus large differences of the flow variations) were chosen to show this effect more clearly. A sudden increase in the COV is found at $0.2 \mathrm{~ms} \mathrm{ASOI}_{\mathrm{a}}$ for $2000 \mathrm{rpm}$, while the magnitude of COV is constant for $333 \mathrm{rpm}$. This demonstrates that the in-cylinder flow becomes sufficiently strong to impact the spray structure at $2000 \mathrm{rpm}$. These observations of spray variations motivate simultaneous measurement of flow and spray structures, as discussed below.

\subsection{Flow/spray interaction and its effect on combustion variability}

Figures 4 and 5 demonstrate the flow/spray interactions for test 5. The PIV measurements focused on the tumble plane between the spark plug and the injector tip. The laser sheet illuminated both liquid spray and PIV-seeds during the injection, so flow and spray structures were imaged simultaneously. The spatially averaged kinetic energy (KE) of the gas flow was calculated to represent the flow energy for analysis (excluding vectors computed in the spray), as defined in Eq. 1. The lefthalf of each vector field is not shown and is not included in the KE-calculation due to the obscuration by soot deposits. $u$ and $v$ are the $\mathrm{x}$ - and $\mathrm{y}$-velocity components of vectors with indices $i$ and $j$ on a 2D grid, $m \times n$ in size. $k$ represents the number of the cycle. To quantify the flow direction, spatial average of all vectors in the dashed rectangle indicated in Fig. 5 is calculated and the direction of this averaged vector is defined as flow angle. According to vector fields shown in Ref. [6], the 
tumble center is located at the spark-plug gap just before injection. Therefore, the direction of the tumble flow for the portion at the right side of the tumble center can be captured and represented using the chosen rectangular region. Along with the flow angle, the included angle of the spray is also quantified based on the SAE-J2715 standard.

$K E_{k}=\frac{1}{n \times m} \sum_{i}^{n} \sum_{j}^{m}\left(u_{i, j, k}^{2}+v_{i, j, k}^{2}\right)$

The effect of injection on flow development is discussed in Ref. [6] based on the PIV and spray measurements of non-fired operations. It has been concluded that the fuel-injection process significantly dominates and decreases variability of the incylinder flow. Here, we focus on fired operation and observe the similar phenomenon of flow variations to the spray alone results shown in Ref. [6]. This indicates that the observed flow variation shown in Fig. 4 is regardless of the ignition and early flame early kernel growth. The top section of Fig. 4 shows that cycle-to-cycle variations of the flow remain high for CAs after $\mathrm{SOI}_{\mathrm{a}}$. Three selected cycles in Figs. $4 \& 5$ exemplify the combined effects of flow and spray. Figure 5 shows different combinations of flow/spray-structures and flow energy. In example 1, a high KE during injection corresponds to a small spray angle and large flow angle. On the contrary, examples 2 and 3 show that low flow energy corresponds to a large spray angle and small flow angle. Hence, it is observed that different types of the flow/spray interactions exist.

In Fig. 5, the spray angles of examples $1 \& 3$ are smaller than the nominal included spray angle of the injector $\left(60^{\circ}\right)$, indicating a certain degree of spray collapse [11]. Meanwhile, the spray angle varies significantly from cycle to cycle, in agreement with the spray variations observed in Fig. 3. However, both the role of the flow for the spray collapse, and the impact of the collapse on subsequent gas-flow entrainment remain unclear. Further studies are required for a better understanding of these cycle-to-cycle variations.

In the following, statistical analysis is used to correlate the flow and spray structures with both the KE of the flow during injection and with the appearance of partial-burn cycles. This involves combining the spray angle at $-17^{\circ} \mathrm{CA}$ with the flow angle at $-21^{\circ} \mathrm{CA}$, as identified in Fig.5 and plotted in Fig.6. There are two important observations. First, cycles characterized by small spray angles with large flow angles (before injection) exhibit high KE (top 15\%) and burn well. Second, all partialburn cycles are heavily biased toward large spray angles $\left(>52.5^{\circ}\right)$ and small flow direction angles $\left(<100^{\circ}\right)$. These observations reveal that the flow energy during injection correlates to some degree with the combined effects of the flow and spray angles. It is then possible that a proper flow direction before injection combined with a more collapsed spray results in a strong interaction between spray and flow to generate high kinetic energy of the flow during injection. These factors are assumed to result in favorable fuel/air-mixing and turbulence levels during the early phase of combustion, which leads to a high burn rate and ensures a more complete combustion event. 


\subsection{Correlations between flow energy and combustion performance}

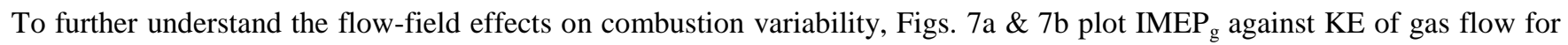
the 140 individual cycles from test 5 (unstable operation with $\left[\mathrm{O}_{2}\right]=19 \%$ ). Figure 7 a shows no apparent trend, possibly illustrating that there is no direct correlation between the combustion performance and the pre-injection tumble flow, as measured in this PIV plane. However, Fig.7b plots KE during injection and shows that all cycles with relatively high KE $\left(>63 \mathrm{~m}^{2} / \mathrm{s}^{2}\right)$ have normal IMEP $\mathrm{g}_{\mathrm{g}}$ values (around $260 \mathrm{kPa}$ ) and are considered to burn well. All partial-burn cycles $(<222 \mathrm{kPa})$ exhibit relatively low KE. This suggests that low flow energy during injection is a predictor of increased likelihood for partial-burn cycles. Still, most cycles with low KE burn well. Given the 3-D nature of both flow and combustion, it is natural that flow variations in the measurement plane are not the only cause of cycle-to-cycle combustion variability.

Based on the observations for the spray and flow structures (Figs. $5 \& 6$ ) and the correlation between the flow energy during injection and the $\operatorname{IMEP}_{\mathrm{g}}$ (Fig. 7), the flow/spray interactions can be classified into two important types, as stated in Table 2. The ranges of KE, flow and spray angles for the strong-flow cycles are determined from the top $15 \%$ KE cycles shown in Fig. 6, while those for the weak-flow cycles are determined from the partial-burn cycles. All strong-flow cycles burn well, while $30 \%$ of all weak flow cycles develop into partial burns.

To understand how the flow affects the combustion rate, AHRR data are compared for normal (FMFB $>80 \%)$ and partial-burn cycles using conditional analysis based on the flow and spray conditions shown in Table 2. Figure 8a plots the AHRR curves for the three examples. Example 1 (well burning cycle with high KE) exhibits high AHRR during the early burn (from ST to $\left.-5^{\circ} \mathrm{CA}\right)$. It is speculated that high flow energy during injection causes favorable fuel/air-mixing and turbulence levels, thus leading to fast flame kernel formation and flame propagation. Examples $2 \& 3$ both exhibit relatively slow early burn phases, which is consistent with the relatively low flow energy during injection. However, example 2 burns completely, whereas example 3 develops into a partial burn. These results are similar to observations by Peterson et al. [12] in that having a slow early burn with low flow energy is a necessary, but not sufficient, condition for the development of partial burns.

Figure $8 \mathrm{~b}$ plots in detail the early AHRR for the top-15\% KE cycles and the 7 partial-burns cycles which have small KE. Figure $8 \mathrm{~b}$ agrees with Figs. 7 and $8 \mathrm{a}$ and indicates that, statistically, high KE corresponds to higher-than-average early AHRR, ensuring a well burning cycle. In contrast, all partial-burn cycles have low early AHRR and delayed transition into the main combustion, consistent with a small KE during injection. Overall, these observations show the importance of the flow during injection for the early stages of stratified combustion using head ignition for low- $\mathrm{NO}_{\mathrm{x}}$ operation with EGR (test $\left.5,\left[\mathrm{O}_{2}\right]=19 \%\right)$. 
As a contrast to the unstable operation with EGR, Fig. 8c presents the AHRR curves for stable operation without EGR in test $4\left(\left[\mathrm{O}_{2}\right]=21 \%\right)$. Using the thresholds in Table 2, 10 strong-flow cycles and 10 weak-flow cycles are identified among 70 cycles. However, for this relatively stable operation $\left(\left[\mathrm{O}_{2}\right]=21 \%\right)$, the flow strength is not a predictor of the magnitude of the early AHRR, and all cycles eventually burn to completion. Apparently, the higher $\left[\mathrm{O}_{2}\right]$ level for this condition makes the early combustion insensitive to flow variations.

\subsection{Effects of flow/spray interactions and EGR on early flame variability}

This section describes the use of flame imaging to quantify the cyclic variability of the early-flame growth as impacted by flow strength and EGR. Figure 9 shows two cycles indicating that the flame growth is faster with higher $\left[\mathrm{O}_{2}\right]$. Hence, to compare the two tests for timings with similar flame size and $\mathrm{AHRR}$, flame images at $-13^{\circ} \mathrm{CA}$ for test 4 and at $-9^{\circ} \mathrm{CA}$ for test 5 are used for Fig.10.

Thresholding is applied to the flame images to define the extent and location of the flame in each cycle and to create ensemble-sampled 2D probability maps, as per Ref. [13]. Conditionally sampled flame-probability maps are shown in Fig. 10 for cycles with strong flow, weak flow, and weak flow with partial burns. Here, flow strength is defined as for Fig. 8. For strong-flow cycles (Figs. 10a \& 10c), large, comparatively radially symmetric, and contiguous high-probability regions are observed and centered just to the left of the ground strap for both $\left[\mathrm{O}_{2}\right]$ levels. The equivalence of Figs.10a \& 10c indicates that the early flame growth is not hampered by a reduction of $\left[\mathrm{O}_{2}\right]$ when the flow is sufficiently strong. For the cycles with $\left[\mathrm{O}_{2}\right]=21 \%$ and weak flow shown in Fig. 10b, it is observed that statistically the flame still develops circularly despite the weak flow. However, for the lower $\left[\mathrm{O}_{2}\right]$ in Fig. 10d, there is a clear tendency for the weak-flow cycles to develop reliably only in a small region to the left of the spark plug. Note that Fig. 10d is based on all 25 weak-flow cycles, including 7 that are partial burns since all partial burn cycles have weak flow, as shown in Figs. 6\&7. Figure 10e samples the 7 partial burns alone. Here, it becomes obvious that the probability of a flame is restricted to a very small region on the left side of the spark plug. The observations in Fig. 10 reveal that the effects of flow/spray-interactions on flame propagation become stronger for low- $\mathrm{NO}_{\mathrm{x}}$ operation with EGR as a result of a weaker early flame kernel and less robust flame structure at lower $\left[\mathrm{O}_{2}\right]$. This occasionally degrades the consumption of the fuel/air mixture, causing partial burn cycles, supporting the hypothesis in section 3.1.

Comparisons among Figs. 10c-e and further inspection of the pressure-based HRR curves in Fig. 8 reveal that most of the weak-flow cycles have sufficient combustion and that the most probable flame develops in the same direction as the wellburning cycles, independent of flow strength. Therefore, it can be surmised that the flow strength (in this measurement 
plane) is not the cause of the slow growth but an indicator of another change. Since increased $\left[\mathrm{O}_{2}\right]$ (in an otherwise statistically equivalent fuel concentration and flow) also ensures complete combustion, it indicates that partial burns are due to changes in the transition from the flame kernel to a fully developed flame. Possibilities include flow-induced flame stretch or over-mixing in the tail of the spray due to the delayed kernel-to-turbulent-flame transition.

\section{Conclusions}

For engine operation at $2000 \mathrm{rpm}$, the in-cylinder air flow generated by the intake and compression strokes is sufficiently strong to cause cycle-to-cycle variability of stratified combustion when EGR is applied to achieve low $\mathrm{NO}_{\mathrm{x}}$ emissions. PIV, spray- and flame-imaging are used to elucidate the in-cylinder mechanisms leading to undesirable partial-burn cycles. Conditional analysis reveals two types of flow/spray-interactions, which can be used to predict likelihood for a particular cycle to develop into a partial burn; 1) a proper flow direction before injection with a more collapsed spray causes strong flow/spray interactions, ensuring high kinetic energy of the flow during injection. This typically leads to a fast early burn, which ensures complete combustion, even for operation with EGR. 2) An improper flow direction and a less collapsed spray generate low flow energy during injection. For this type of flow/spray-interaction, here, $30 \%$ of the cycles develop into partial burns when EGR is applied. Hence, having weak gas flow near the fuel spray during injection is thought to be one mechanism that contributes to the appearance of partial-burn cycles.

Flame-probability maps reveal that the partial-burn cycles for operation with EGR have a weak and variable flame development. Without EGR, the flame development away from the spark plug is more repeatable regardless of the type of flow/spray-interaction, at the expense of higher $\mathrm{NO}_{\mathrm{x}}$ emissions.

\section{Acknowledgements}

Financial support was provided by the U.S. Department of Energy, Office of Vehicle Technologies. Sandia is a multiprogram laboratory operated by the Sandia Corporation, a Lockheed Martin Company, for the United States Department of Energy's National Nuclear Security Administration under contract DE-AC04-94AL85000.

\section{Reference}

1. H. Ando, C. Arcoumanis, Flow and Combustion in Reciprocating Engines, Springer-Verlag, Berlin Heidelberg, 2008, p. 137, Chapter.3.

2. M.C. Drake, D.C. Haworth, Proc. Combust. Inst. 31 (2007) 99-124. 
3. M. Sjöberg, D.L. Reuss, SAE Int. J. Fuels Lubr. 5 (2012) 1096-1113.

4. M. Sjöberg, D.L. Reuss, Proc. Combust. Inst. 34 (2013) 2933-2940.

5. M. Sjöberg, W. Zeng, D. L. Reuss, SAE Int. J. Engines 7 (2014).

6. W. Zeng, M. Sjöberg, D. L. Reuss, SAE Int. J. Engines 7 (2014).

7. R. Stiehl, J. Schorr, C. Krüger, A. Dreizler, B. Böhm, $25^{\text {th }}$ European Conference on Liquid Atomization and Spray Systems (2013)

8. R. Stiehl, J. Schorr, C. Krüger, A. Dreizler, B. Böhm, Flow Turbulence Combust. 91 (3) (2013) 431-450

9. J.B. Heywood, Internal Combustion Engine Fundamentals, McGraw-Hill, New York, 1988.

10. M. Sjöberg, W. Zeng, D. L. Reuss, 2013 Hyundai-Kia International Powertrain Conference.

11. W. Zeng, M. Xu, G. Zhang, Y. Zhang, D.J. Cleary, Fuel 95 (2012) 287-297.

12. B. Peterson, D.L. Reuss, V. Sick, Proc. Combust. Inst. 33 (2011) 3089-3096.

13. W. Zeng, C.A. Idicheria, T.D. Fansler, M.C. Drake, SAE Technical Paper 2011-01-1281, 2011. 
Table 1

Engine specifications and operating conditions

\begin{tabular}{|c|c|c|c|}
\hline \multicolumn{4}{|c|}{ Bore/Stroke/ Displacement (liter) } \\
\hline \multicolumn{3}{|c|}{ CR/Swirl/Tumble Ratios } & $12: 1 / 2.7 / 0.6$ \\
\hline \multicolumn{2}{|l|}{ Ave Ign Energy / Dur } & & $106 \mathrm{~mJ} / 1.0 \mathrm{~ms}$ \\
\hline Fuel injector & \multicolumn{3}{|c|}{ Bosch 8-hole w $/ 60^{\circ}$ included angle } \\
\hline \multicolumn{2}{|c|}{ Injection-duration/Fuel-mass } & \multicolumn{2}{|c|}{$0.925 \mathrm{~ms} / 12.6 \mathrm{mg}$} \\
\hline \multicolumn{2}{|c|}{ Intake / coolant temperatures } & \multicolumn{2}{|c|}{$25-28^{\circ} \mathrm{C} / 60^{\circ} \mathrm{C}$} \\
\hline \multicolumn{2}{|c|}{ Injection Pressure/Fuel } & \multicolumn{2}{|c|}{$17 \mathrm{MPa} / \mathrm{E} 70$} \\
\hline \multicolumn{2}{|l|}{ Intake pressure (abs.) } & \multicolumn{2}{|c|}{$95 \mathrm{kPa}$} \\
\hline Test Configuration & {$\left[\mathrm{O}_{2}\right]$} & $\mathrm{SOIe} / \mathrm{SOIa} / \mathrm{ST} *\left({ }^{\circ} \mathrm{CA}\right.$ & $R P M$ \\
\hline 1.All-metal & $21 \%$ & $-20 /-16 /-14$ & 2000 \\
\hline 2.All-metal & $20 \%$ & $-22 /-18 /-16$ & 2000 \\
\hline 3.All-m & $19 \%$ & $-25 /-21 /-19$ & 2000 \\
\hline 4.PIV/flame/spray & $21 \%$ & $-25 /-21 /-19$ & 2000 \\
\hline 5.PIV/flame/spray & $19 \%$ & $-25 /-21 /-19$ & 2000 \\
\hline 6.Spray alone & $21 \%$ & $-22.8 /-18.6 / \sim$ & 2000 \\
\hline 7.Spray alone & $21 \%$ & $-22.8 /-22.2 / \sim$ & 333 \\
\hline
\end{tabular}

Table 2

Classification of flow/spray interaction

\begin{tabular}{llll}
\hline & KE$^{*}$ & Flow angle & Spray angle \\
\hline Strong flow & $>86 \mathrm{~m}^{2} / \mathrm{s}^{2}$ & $>100^{\circ}$ & $<52.5^{\circ}$ \\
Weak flow & $<63 \mathrm{~m}^{2} / \mathrm{s}^{2}$ & $<100^{\circ}$ & $>52.5^{\circ}$ \\
\hline
\end{tabular}

*KE only reflects the flow during injection. 


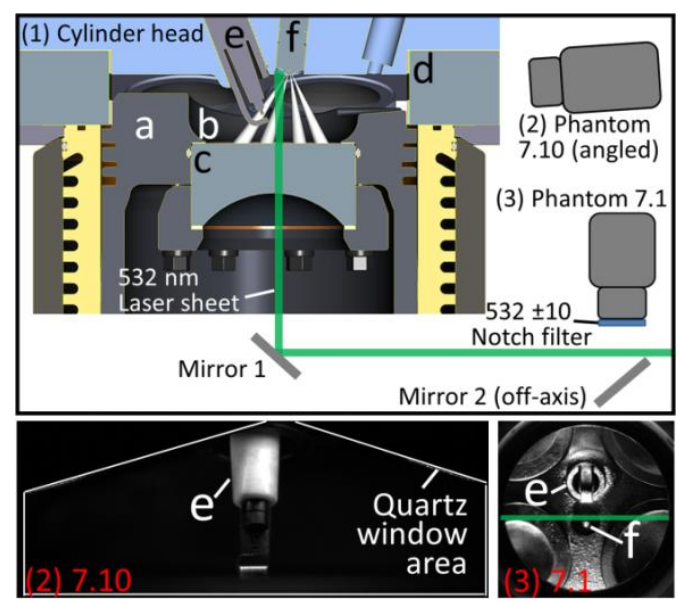

Fig.1. (1) single-cylinder optical engine with (a)-piston, (b)-piston bowl, (c)-piston-bowl window, (d)-pent-roof window, (e)spark plug, and (f)-fuel injector, (2) camera view for PIV, (3) camera view for flame imaging.

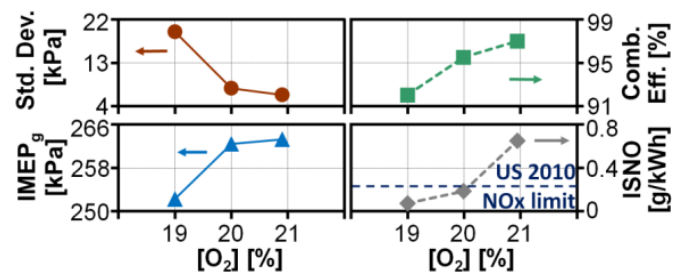

Fig.2. Combustion efficiency, $\mathrm{IMEP}_{\mathrm{g}}$, standard deviation of $\mathrm{IMEP}_{\mathrm{g}}$ and $\mathrm{NO}$ emission for all-metal engine operation obtained by sweeping intake $\left[\mathrm{O}_{2}\right]$ at $2000 \mathrm{rpm}$.
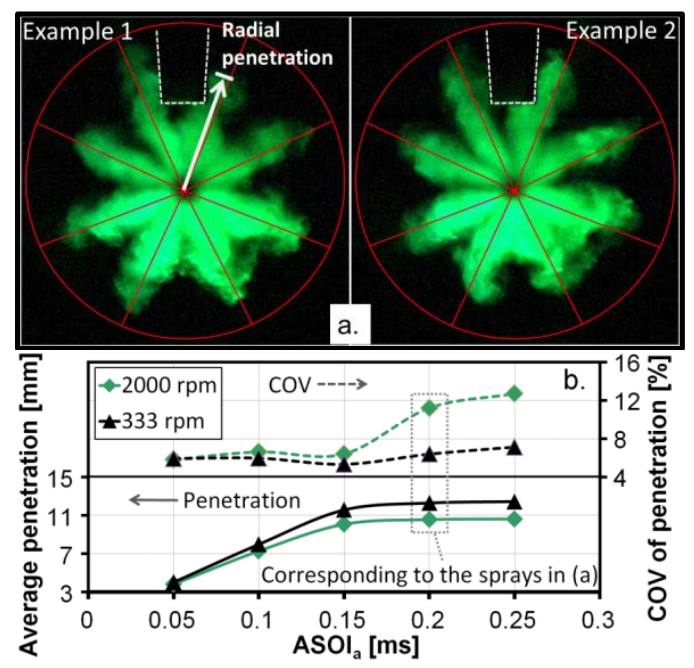

Fig.3. (a) two individual spray images recorded $0.20 \mathrm{~ms} \mathrm{ASOI}_{\mathrm{a}}$ at $2000 \mathrm{rpm}$, test 6 . The overlay is for reference and indicates the expected jet trajectories. (b) Averaged radial penetration of 1:00-jet and its COV for both $333 \mathrm{rpm}$ (test 7) and $2000 \mathrm{rpm}$ (test 6). 


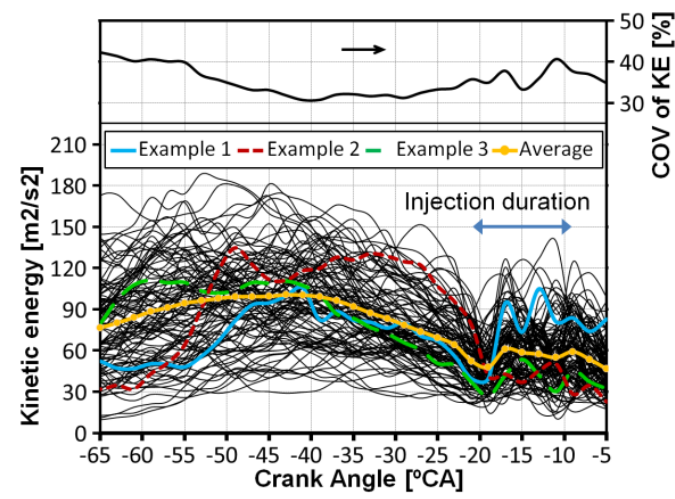

Fig.4. Spatially-averaged kinetic-energy (KE) for 140 cycles and its $\mathrm{COV}$ at $2000 \mathrm{rpm}$ with $\left[\mathrm{O}_{2}\right]=19 \%$, test 5 .
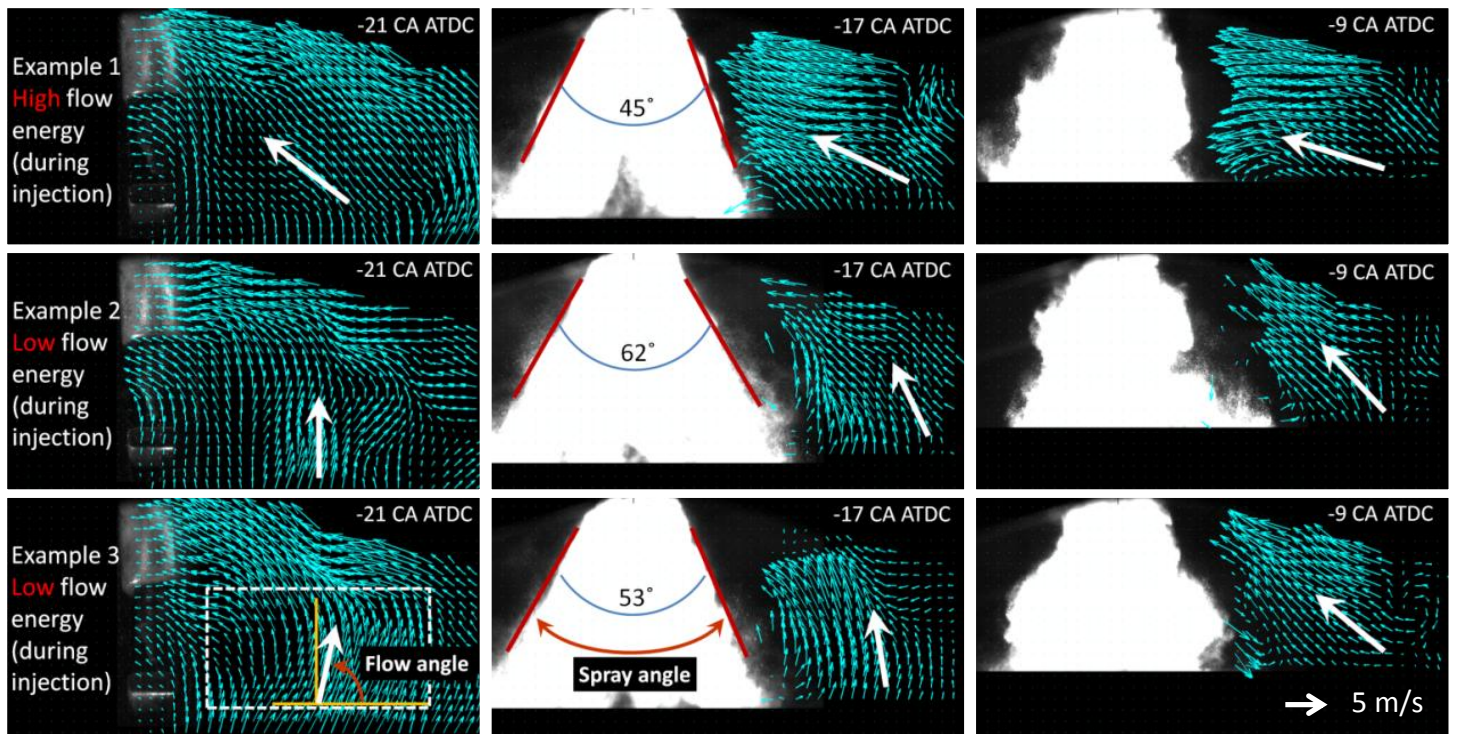

Fig.5. Flow field evolutions with spray structures for the three specially selected cycles indicated in Fig.4.

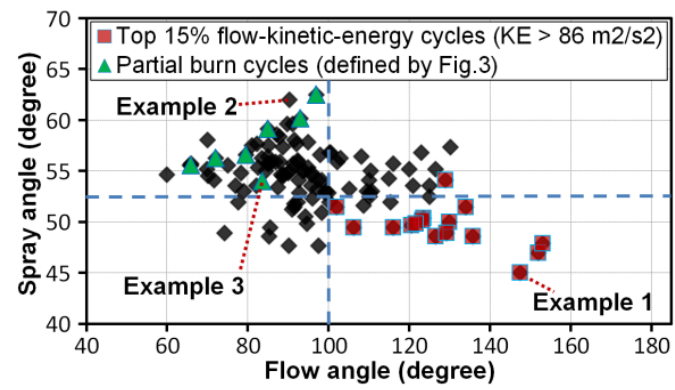

Fig.6. Spray and flow angles for 140 individual cycles at $2000 \mathrm{rpm}$ operation with $\left[\mathrm{O}_{2}\right]=19 \%$ (test 5) and kinetic energy of the flow during injection and with partial-burn cycles. 


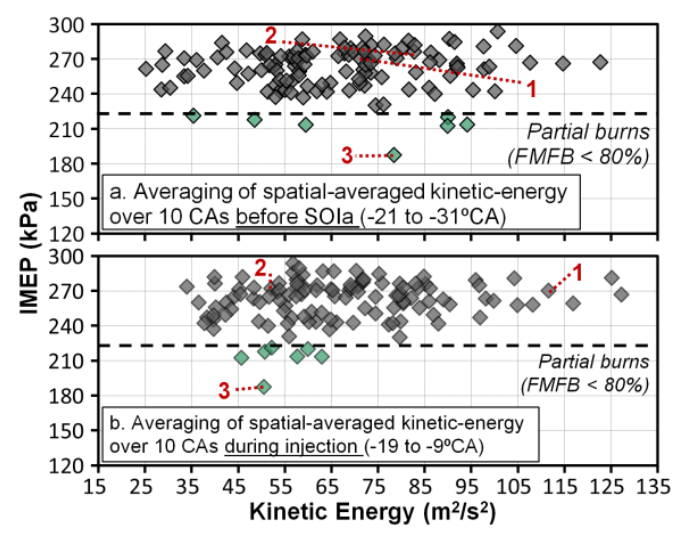

Fig.7. IMEP ${ }_{g}$ against spatially averaged $\mathrm{KE}$ of gas flow, averaged over $10^{\circ} \mathrm{CA}$ before $\mathrm{SOI}_{\mathrm{a}}$ (a) and during injection (b), test 5 .

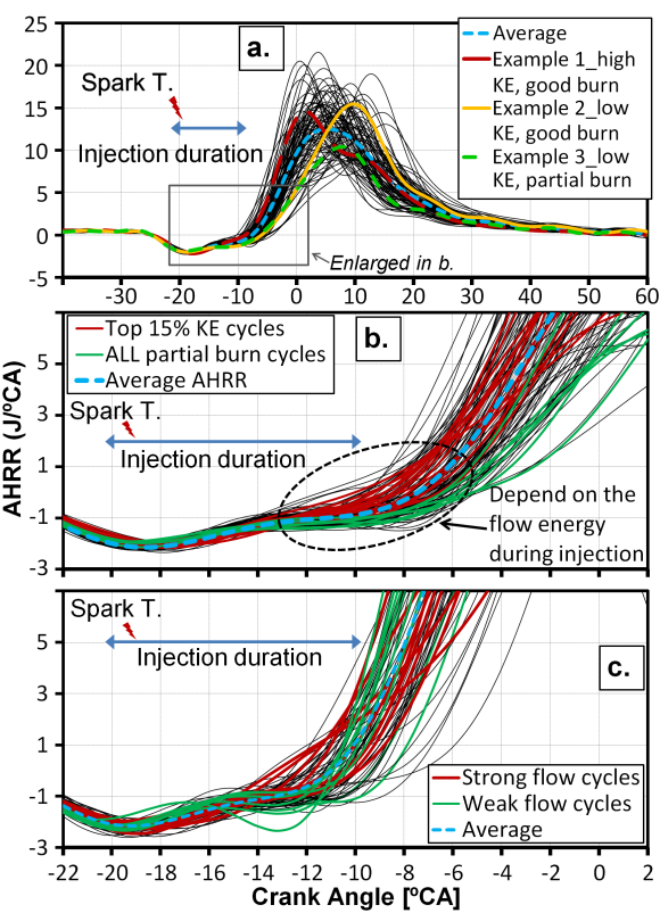

Fig.8. (a) AHRR curves for $\left[\mathrm{O}_{2}\right]=19 \%$, test 5, highlighting the three examples shown in Figs. 4-7, (b) early AHRR with $\left[\mathrm{O}_{2}\right]$ $=19 \%$, test 5 , highlighting the top- $15 \% \mathrm{KE}$ cycles and all partial-burn cycles, and (c) early AHRR curves with $\left[\mathrm{O}_{2}\right]=21 \%$, test 4 , highlighting all strong- and weak-flow cycles. 


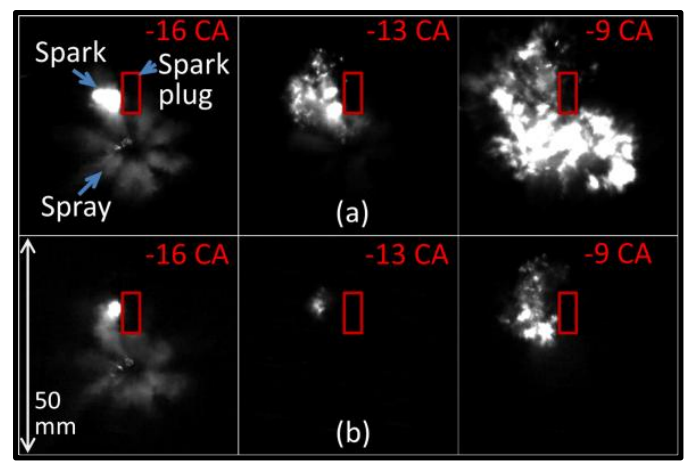

Fig.9. Comparison of early flame propagation for statistically selected cycles from (a) test 4 , $\left[\mathrm{O}_{2}\right]=21 \%$, and (b) test 5 , $\left[\mathrm{O}_{2}\right]$ $=19 \%$. Images at $-16^{\circ} \mathrm{CA}$ include LED illumination of the liquid spray. Rectangle indicates the projection of the spark-plug ground strap.

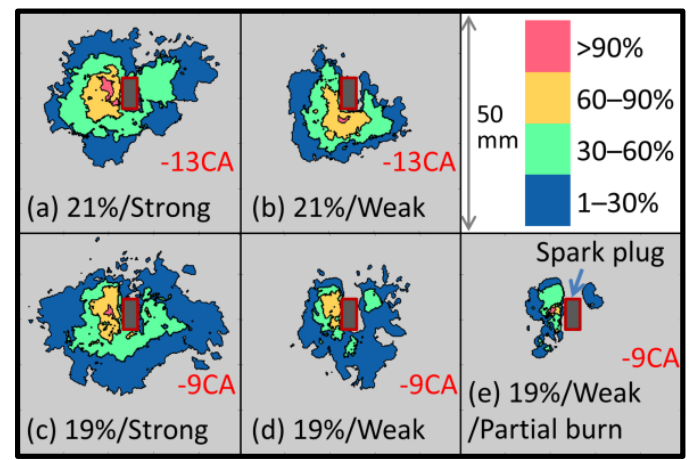

Fig.10. Probability maps of flame development for (a) 10 strong-flow and (b) 10 weak-flow cycles with $\left[\mathrm{O}_{2}\right]=21 \%$, (c) 20 strong-flow, (d) 25 weak-flow, and (e) 7 partial-burn cycles with $\left[\mathrm{O}_{2}\right]=19 \%$. Rectangle indicates the projection of the spark-plug ground strap. 
Fig.1. (1) single-cylinder optical engine with (a)-piston, (b)-piston bowl, (c)-piston-bowl window, (d)-pent-roof window, (e)spark plug, and (f)-fuel injector, (2) camera view for PIV, (3) camera view for flame, (4) camera view for liquid-spray.

Fig.2. Combustion efficiency, $\mathrm{IMEP}_{\mathrm{g}}$, standard deviation of $\mathrm{IMEP}_{\mathrm{g}}$ and NO emission for all-metal engine operation obtained by sweeping intake $\left[\mathrm{O}_{2}\right]$ at $2000 \mathrm{rpm}$.

Fig.3. (a) two individual spray images recorded $0.20 \mathrm{~ms} \mathrm{ASOI}$ at $2000 \mathrm{rpm}$, test 6 . The overlay is for reference and indicates the expected jet trajectories. (b) Averaged radial penetration of 1:00-jet and its COV for both $333 \mathrm{rpm}$ (test 7 ) and $2000 \mathrm{rpm}$ (test 6).

Fig.4. Spatially-averaged kinetic-energy (KE) for 140 cycles and its $\mathrm{COV}$ at $2000 \mathrm{rpm}$ with $\left[\mathrm{O}_{2}\right]=19 \%$, test 5 .

Fig.5. Flow field evolutions with spray structures for the three specially selected cycles indicated in Fig.4.

Fig.6. Spray and flow angles for 140 individual cycles at $2000 \mathrm{rpm}$ operation with $\left[\mathrm{O}_{2}\right]=19 \%$ (test 5) and kinetic energy of the flow during injection and with partial-burn cycles.

Fig.7. $\mathrm{IMEP}_{\mathrm{g}}$ against spatially averaged $\mathrm{KE}$ of gas flow, averaged over $10^{\circ} \mathrm{CA}$ before $\mathrm{SOI}_{\mathrm{a}}(\mathrm{a})$ and during injection (b), test 5 . Fig.8. (a) AHRR curves for $\left[\mathrm{O}_{2}\right]=19 \%$, test 5, highlighting the three examples shown in Figs. 4-7, (b) early AHRR with $\left[\mathrm{O}_{2}\right]$ $=19 \%$, test 5 , highlighting the top- $15 \% \mathrm{KE}$ cycles and all partial-burn cycles, and (c) early $\mathrm{AHRR}_{\text {curves }}$ with $\left[\mathrm{O}_{2}\right]=21 \%$, test 4 , highlighting all strong- and weak-flow cycles.

Fig.9. Comparison of early flame propagation for statistically selected cycles from (a) test 4, $\left[\mathrm{O}_{2}\right]=21 \%$, and (b) test 5, $\left[\mathrm{O}_{2}\right]$ $=19 \%$. Images at $-16^{\circ} \mathrm{CA}$ include LED illumination of the liquid spray.

Fig.10. Probability maps of flame development for (a) 10 strong-flow and (b) 10 weak-flow cycles with $\left[\mathrm{O}_{2}\right]=21 \%$, (c) 20 strong-flow, (d) 25 weak-flow, and (e) 7 partial-burn cycles with $\left[\mathrm{O}_{2}\right]=19 \%$. 